\title{
Incidence of Acceptance and Reasons of Refusal of PPIUCD in A Tertiary Care Hospital
}

\author{
FAIZA GHAFOOR ${ }^{1}$, MUNTIHA SAROSH ${ }^{2}$, NADIA ZAHID ${ }^{3}, K O K A B$ ZIA ${ }^{4}$, UZMA MANZOOR ${ }^{5}$, UZMA SHAHZAD \\ ${ }^{1}$ Senior Registrar, Obs \& Gynae, Avicenna Medical College, Lahore \\ ${ }^{2,3,4}$ Associate Professor Obs \& Gynae, Avicenna Medical College, Lahore \\ ${ }^{5,6}$ Assistant Professor Gynae \& Obs, Independent Medical College, Faisalabad \\ Correspondence: Dr. Muntiha Sarosh, H 492 , Block D ,Street \# 14 ,Phase 6,DHA ,Lahore, E- mail : krehman01@yahoo.com
}

\begin{abstract}
Aim: To determine the incidence of acceptance and the reasons of refusal of PPIUCD in antenatal and post natal women.

Study Design:Cross sectional study.

Place \& duration of study: The study was conducted in the department of Obs. \&Gynae ,Avicenna Hospital , Lahore for the period of One year (Jan 2019 to Dec 2019).

Methodology: After approval from the ethical committee of Avicenna Hospital Lahore, 108eligible pregnant women attending the OPD and labor room were enrolled in the study. Informed consent was taken. Nonprobability convenience sampling technique was used. Afterwards they were counseled for PPIUCD and a validated questionnaire including age, parity, educational and socioeconomic status, awareness of PPIUCD, willingness for PPIUCD insertion and reasons of refusal was used to collect data. Logistic regression analysis was used to find out significance of the above-mentioned factors.

Results: The mean age of the woman was 26.7 years with the standard deviation of 4.4 .Only $24 \%$ women were aware of PPIUCD . Acceptance rate of PPIUCD was $12.96 \%$ and $67.59 \%$ refused PPIUCD , while $19.44 \%$ were convinced but wanted to discuss the family .Prior awareness of PPIUCD was a strong predictor for acceptance therefore the women who had no prior knowledge about the method were the most to refuse $69.04 \%$. On enquiring husband / Family's disagreement was found to be the most frequent reason for refusal . $(29.7 \%)$.Many of the ladies wanted Permanent Method for contraception and other were more concerned regarding the risk of complication . Refusal rate was highest amongst P0 and Primipara ladies ,64.28 \% and $62.50 \%$ respectively .

Conclusion: The awareness about availability of PPIUCD is quite low because it is recently introduced in the family planning methods. The acceptance rate of PPIUCD after dedicated counseling is good despite low awareness. The most frequent reason of refusal is husband and family disagreement. The acceptance can further be enhanced by dissemination of information and appropriate counseling in antenatal clinic.

Key words: Awareness, Acceptance, Reasons Of Refusal, PPIUCD
\end{abstract}

\section{INTRODUCTION}

Pakistan is sixth most populous country in the world having an estimated population of 191.71 million in 2015. It is expected that Pakistan would become fifth most populous country by 2050 . The population boom is not only responsible for economic upheaval but it is leading us into an era of shortage of health \& education facilities, shortage of drinking water, overcrowding, poverty, crime and environmental degradation ${ }^{1}$.

Recognizing the potential impact of improved family planning, a sustainable and effective family planning program is desperately required. The present total fertility rate (TFR) in Pakistan is 3.6 births, which lags behind the target of 2.1. The contraceptive prevalence rate (CPR) in Pakistan is $34.2 \%$. Unmet need of contraception in Pakistan is $17.3 \%{ }^{2}$. The recommended interval between pregnancies is 24 month $^{3}$. There is a high rate of un intended pregnancy as well especially postpartum women. So there is need for an effective, long term contraceptive method.$^{4}$ In our country delivery might be the only time a healthy women comes in contact with health personnel. The postpartum period is a critical window of opportunity to address unmet family planning need. PPIUCD is the best choice for noncompliant populations like ours; as it enables

Received on 12-11-2018

Accepted on 24-04-2020 the lady leave hospital with a safe, effective, long acting, and reversible method already in place $^{5,6}$. It is recommended by $\mathrm{WHO}$ as well ${ }^{7}$.

In spite of the skilled counseling about the effectiveness, safety \& benefits of PPIUCD insertion, lack of enthusiasm of patients towards IUCD insertion led us to explore the magnitude of awareness and acceptance rate of PPIUCD and reasons behind hesitancy of patients to accept PPIUCD in our population. Although international literature related to the issue is available but country based data is limited. Due to different social background, myths and religious beliefs the dynamics of PPIUCD refusal may differ in our country. Knowing the reservations, myths and fears of our population, we may address them better in counseling sessions to improve the acceptance and satisfaction rate ${ }^{8}$.

In Pakistan PPIUCD has been introduced in health care system since 2012 and efforts are being put by green star, NCMNH, Jhpiego and USAID to institutionalize the service. Keeping in view the recent entry of this service in our health system, awareness and acceptance are expected to be low.Objective of my study is to determine the awareness, acceptance and the reasons of refusal of PPIUCD in women presenting in OPD, antenatal ward or labor room of a tertiary care hospital. 


\section{METHODOLOGY}

It was a cross sectional study conducted in the department of Obs. \&Gynae ,Avicenna Hospital, Lahore for the period of One year (Jan 2019 to Dec 2019). Having approval from the ethical committee of the Avicenna Hospital Lahore, 108 eligible pregnant women attending the OPD and labor room were included in the study after taking informed consent. Non-probability convenience sampling technique was used. Women of 18 to 45 years age, with any parity, desiring contraception and eligible for IUCD according to WHO medical eligibility criteria (MEC) were enrolled in the study.11 women who had chorioamnionitis, prolonged leaking (>18 hours), puerperal sepsis, postpartum hemorrhage, dai handling or any other contraindication according to WHO MEC criteria were not included in the study. Women were counseled on postpartum contraception during antenatal care visits in OPD, antenatal ward or during their admission to labor room in early labor. Dedicated PPIUCD counselors and postgraduate trainees who got standardized training for PPIUCD counseling interviewed and counseled the patients. Patients were asked about awareness of PPIUCD, afterwards they were counseled about PPIUCD and offered the service, those who rejected were interviewed about reasons of refusal. A validated questionnaire including age, parity, educational and socioeconomic status, number of sons, awareness of PPIUCD, willingness for PPIUCD insertion and reasons of refusal was used to collect data. Data was entered and analyzed in SPSS version 22. Mean and standard deviation was calculated for quantitative variable like age of the women. Qualitative variables like acceptance, reasons for rejection of PPIUCD, socioeconomic and education status and awareness of PPIUCD were analyzed as frequencies and percentages. Stratification for age, parity, number of sons, socioeconomic and education status was done to address the effect modifiers. Post stratification chi square test was applied with $p$ - value $<0.05$ taken as significant.

Operational definition: PPIUCD insertion (postpartum intrauterine contraceptive device) was defined as insertion of IUCD within 48 hours of birth. Acceptance rate was defined as the number of ladies who agreed to have postpartum IUCD placement after counseling. Awareness was defined as knowing IUCD insertion in first 48 hours after delivery as a contraceptive option.

\section{RESULTS}

A Total of 108 women were interviewed and counseled. Table 1 shows the demographic characteristics of the women and enrolled in the study. The mean age of the woman was 26.7 years with the standard deviation of 4.4. The majority of the women were para 2-4 (56.4\%). Over all $46.2 \%$ women were un educated while rest of them had education to different level .Majority belong to lower socio economic class $(60.1 \%)$. Acceptance rate was found to be $(12.96 \%)$ and women who refused for PPIUCD were (7.59\%). More over $19.44 \%$ women were convinced to have PPIUCD insertion but they further wanted to take opinion of family. Refusal was highest (76.19\%) (65.57\%) amongst the younger age group of (15--25 years) and (2635 years) with a $p$-value less than 0.05 , for both groups .Women with less parity as P0 and P1 were also among the highest to refuse $(64.28 \%),(62.50 \%)$ respectively , which is quite obvious and significant in the study ( $p$-value less than 0.05 ) respectively for either group .Considering the educational status the women belonging to uneducated and primary educational group significantly showed a higher refusal rate (Table 2).

Prior awareness of PPIUCD was a strong predictor for acceptance therefore the women who had no prior knowledge about the method were the most to refuse $(69.04 \%)$ p-value less than 0.05 . On enquiring husband / Family's disagreement was found to be the most frequent reason for refusal(29.7\%). Many of the ladies wanted Permanent Method for contraception and other few were more interested in short term spacing method. Thus leading to non- acceptance of PPIUCD as shown in Figure 1.

Table 1 : Demographic Characteristics of Patients $(n=108)$

\begin{tabular}{|c|c|c|}
\hline Characteristics & $\mathbf{N}$ & \%age \\
\hline \multicolumn{3}{|l|}{ Age ( Years ) } \\
\hline $15-25$ & 42 & 38.88 \\
\hline $26-35$ & 61 & 56.48 \\
\hline $36-45$ & 5 & 4.62 \\
\hline \multicolumn{3}{|l|}{ Parity } \\
\hline Greater than P5 & 9 & 8.33 \\
\hline$P(2-4)$ & 61 & 56.48 \\
\hline P1 & 24 & 22.22 \\
\hline P0 & 14 & 12.96 \\
\hline \multicolumn{3}{|l|}{ Educational Status } \\
\hline Above & 11 & 10.18 \\
\hline Matriculation & 18 & 16.66 \\
\hline Primary & 29 & 26.85 \\
\hline Un-Educated & 50 & 46.29 \\
\hline \multicolumn{3}{|l|}{ Socio Economic Status } \\
\hline Lower & 65 & 60.18 \\
\hline Middle & 38 & 35.18 \\
\hline Upper & 5 & 4.62 \\
\hline & Frequency & \%age \\
\hline Husband/Family Disagree & 32 & 29.7 \\
\hline $\begin{array}{l}\text { Wants Permanent Method like } \\
\text { BTL }\end{array}$ & 26 & 24 \\
\hline Short Term Spacing Required & 19 & 17.6 \\
\hline Fear of side effects & 16 & 14.81 \\
\hline $\begin{array}{l}\text { Satisfied with contraceptive } \\
\text { method }\end{array}$ & 12 & 11 \\
\hline Religious beliefs & 3 & 2.8 \\
\hline
\end{tabular}


Fig. 1: Reason for refusal of PPIUCD

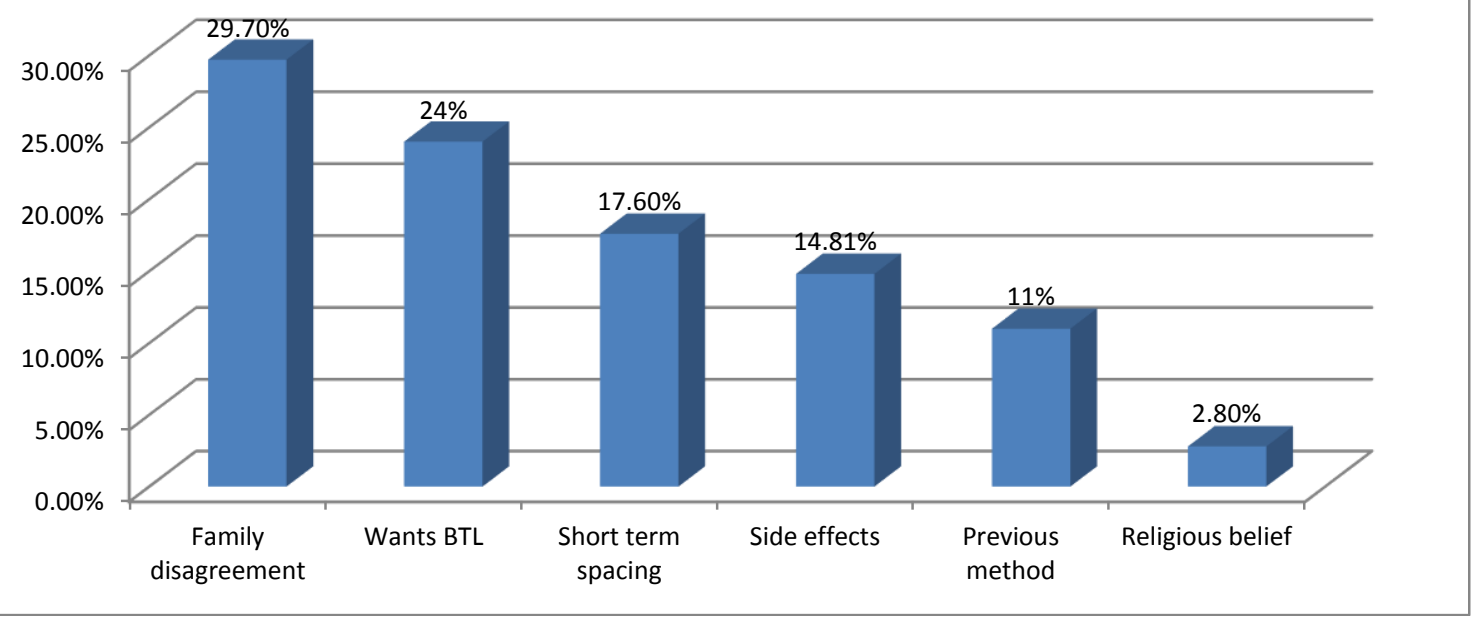

Table 2 : Acceptance according to socio Demographic and Obstetrical Characteristics $(n=108)$

\begin{tabular}{|c|c|c|c|c|c|c|c|}
\hline \multirow{3}{*}{$\begin{array}{l}\text { Characteristics } \\
\text { Patient Number }\end{array}$} & \multirow{2}{*}{$\begin{array}{l}\text { Total } \\
\mathbf{N}\end{array}$} & \multicolumn{2}{|c|}{ Accepted } & \multicolumn{2}{|c|}{ Convinced } & \multicolumn{2}{|c|}{ Refused } \\
\hline & & $\mathbf{N}$ & $\%$ & $\mathbf{N}$ & $\%$ & $\mathbf{N}$ & $\%$ \\
\hline & 108 & 14 & 12.96 & 21 & 19.44 & 73 & 67.59 \\
\hline \multicolumn{8}{|l|}{ Age ( Years ) } \\
\hline $15-25$ & 42 & 3 & 7.14 & 7 & 16.66 & 32 & 76.19 \\
\hline $26-35$ & 61 & 9 & 14.75 & 12 & 19.67 & 40 & 65.57 \\
\hline $36-45$ & 5 & 2 & 40 & 2 & 40 & 1 & 20 \\
\hline \multicolumn{8}{|l|}{ Parity } \\
\hline Greater than P5 & 9 & 3 & 33.33 & 4 & 44.44 & 2 & 22.22 \\
\hline $\mathrm{P}(2-4)$ & 61 & 6 & 59.01 & 8 & 13.11 & 47 & 77.04 \\
\hline $\mathrm{P} 1$ & 24 & 4 & 16.66 & 5 & 20.83 & 15 & 62.5 \\
\hline P0 & 14 & 1 & 7.14 & 4 & 28.57 & 9 & 64.28 \\
\hline \multicolumn{8}{|c|}{ Educational Status } \\
\hline Above & 11 & 4 & 36.36 & 5 & 45.45 & 2 & 18.18 \\
\hline Matriculation & 18 & 7 & 38.88 & 8 & 44.44 & 3 & 16.16 \\
\hline Primary & 29 & 1 & 3.44 & 5 & 17.24 & 23 & 79.31 \\
\hline Un-Educated & 50 & 2 & 4 & 3 & 6 & 45 & 90 \\
\hline \multicolumn{8}{|c|}{ Socio Economic Status } \\
\hline Lower & 65 & 5 & 7.69 & 11 & 16.92 & 49 & 75.38 \\
\hline Middle & 38 & 7 & 18.42 & 8 & 21.05 & 23 & 60.52 \\
\hline Upper & 5 & 2 & 40 & 2 & 40 & 1 & 20 \\
\hline \multicolumn{8}{|c|}{ Awareness of PPIUCD } \\
\hline Yes & 24 & 4 & 16.66 & 5 & 20.83 & 15 & 62.5 \\
\hline No & 84 & 10 & 11.90 & 16 & 19.04 & 58 & 69.04 \\
\hline \multicolumn{8}{|l|}{ Number of boys } \\
\hline 0 & 37 & 6 & 16.21 & 9 & 24.32 & 22 & 59.45 \\
\hline 1 or more & 71 & 8 & 11.26 & 12 & 16.90 & 51 & 71.83 \\
\hline
\end{tabular}

\section{DISCUSSION}

In the present study 108 patients were accessed regarding contraception and PPIUCD. Acceptance rate of PPIUCD is $12.96 \%$ which is comparable to study conducted by Prabha et $\mathrm{al}^{9}$, where the acceptance rate is low, around $8.2 \%$. Anila Tresssa et $\mathrm{al}^{10}$ also revealed a low acceptance rate of $10.5 \%$. Both of these studies are conductedat tertiary care hospitals adjacent to rural areas. Ours is also a tertiary care hospital draining a large rural area. While in contrast acceptance rate is high $51.6 \%$ revealed by Kachan Rani ${ }^{10}$, India in 2018, same is seen in another investigation ${ }^{12}$ where it was found to be $53.27 \%$. Acceptance rate was
$43.86-50 \%$ in a study conducted by Rajuan Doley et al .${ }^{13}$ Possibly because of higher literacy rate, and awareness in the antenatal period.

Main reason of refusal in the present study is found to be family /husband disagreement which is $29.7 \%$. It is comparable to study of SaimaChaudry ${ }^{12}$, may be owing to relatively similar social setup, but it is very high in study of Aruna Nigam at al ${ }^{14}$ as it was conducted in rural area and there was lack ofcounseling for PPIUCD among the family members.While in another study conducted in Ethopia, fear of complications remains the leading cause i.e., $24.8 \%$, religious believes $19.8 \%$ and husband's refusal $17.7 \%{ }^{15}$. 
Cultural differences being the chief cause for this difference. Anila Tressa et $\mathrm{al}^{14}$ also revealed need for a permanent method of contraception as the no 1 reason for refusal , followed by unwillingness of husband, the earlier factor may be due to the greater number of multigravida included in the study $66.2 \%$.

It is also seen that acceptance is high among multigravida patient as compared to Primigravida ${ }^{17}$, It was $88 \%$ in multigravida and $18 \%$ in Primigravida, comparable to our study where refusal of PPIUCD is significant in primiparous women. In present study Awareness of PPIUCD is $30.96 \%$. Awareness of a method is an important factor. Women with prior knowledge are more likely to accept the PPIUCD as in study of Abinaya ${ }^{16}, 44.8 \%$ were aware of the method. Acceptance was high in patient with formal education ${ }^{18}$. But awareness regarding PPIUCD is still low which needs to be increased in order to increase the acceptance of PPIUCD.

\section{CONCLUSION}

Acceptance rate is very low. With better counseling and awareness in antenatal periods regarding family planning PPIUCD acceptance can be improved in population. It needsa lot of effort on the part of medical staff and government. Social media and NGOs like IPAS can play their role. Reason of refusal like unwillingness of husband and fear of complications can be overcome by proper counseling, public awareness programs, social media and greater in put by the government.

\section{REFERENCES}

1. Pakistan economic survey 2014- 2015. Chapter 12, Population, Labor Force and Employment - Ministry of Finance, available www.finance.gov.pk/survey/chapters 15/12 Population.pd

2. Pakistan economic survey 2018-2019. Ministry of Finance, available at. http://www.finance.gov.pk/survey/chapters_12 / executive\%20summary.pdf.

3. Report of WHO Technical Consultation on Birth Spacing. World Health Organization,2006.

4. Nisha S,Sathi MS ,VijayanCP.Post placental insertion of IUD in a tertiary centre. Acceptance of safety . J Evol Med Dent Sci . $2016 ; 5(80): 5933-8$

5. Bai Gujju RL, Prasad U. Study on the acceptance, complications and continuation rate of post partum family planning using theppost placental intrauterine contraception device among women delivering at tertiary care hospital .Int.JReprod .ContraceptObstetGynecol . 2016 Sept ; 5(9); 3195-9.

6. Anjum A ,Shabnum SA, Immeditepost partum IUCD Insertion : An $\mathrm{n}$ Opportunity Not to be missed: ASK \& KMDC 19(1):15;2014.
7. World Health Organization medical eligibility criteria for contraception use[internet].Geneva World Health Organization; $2010 \quad$ Available fromhttp;//www.who.int/reproductivehealth/publications/family planning/9789241563888/en/.

8. Gautam $\mathrm{R}$,Arya $\mathrm{KN}$, Kharakwal $\mathrm{S}$, Singh $\mathrm{S}$, Trived ;M, overview of immediate PPIUCD application in Bundelkhand Region . J Evol Med Dental Sci , 2014;3:9518--26.

9. 9.Prbha Lal, NithaPanday, AbhaSingh, A reterospective analysis on acceptability of PPIUCD insertion, Int $\mathrm{J}$ ReprodContraceptObstetGynaecol 2018;7:4536—9.

10. Kanchan Rani ,Nirmal Kumar Pangtey, Garima Khanna, Mahima Rani, PPIUCD awareness and reason for non acceptance ,Department of obstetrics and gyynaecology,, TeerthandarMahaveer Medical college , Uttrakhand ,India, $27^{\text {th }}$ sept 2018

11. PPIUCD:awareness and reason for non acceptance, AnilaTresaAlukal, ResmyC,Lissiamma George,22 novemeber 2017.Int JReprodContrraceptObstetGyneacol, 2018;7:582-6

12. Saima $\mathrm{C}$, Asmma J, Shamsa $\mathrm{H}$ et al Awareness Acceptance and reason of refusal of PPIUCD in a tertiary care hospital , JFJMC VOL.10 NO.2 APR-Jun 2016.

13. RajanDoley,BornaliPegu. A Retospective study on acceptability and complications Of PPIUCD Insertion. Evolution Med .Dent,Sci/vol.05/issue31/Apr,18,2016 16311634.

14. Aruna Nigam, Ayesha Ahmed and SawarajBatra, postpartum Intrauterine Device Refusal In Delhi :Reason Analyzed, Department of Obstetrics and gynaecology, Hamdard Institute of Medical Science and research, new Dehlilndia ,J Obstet Gyanecol India 2018 Jun 68(3): 208-213.

15. Alemayehu Gonie et al, Acceptability and factors associated with post partum IUCD use among women who gave birth at Bale zone health facilities, Southeast Ethiopia ,contraception and reproductive medicine 3 , Article number 16 (2018):https://doi.org/10.1186/s40834-018-0071-z

16. Abinaya Valliappan ,GowriDorairajan , PalanivelChinnakali, Postpartum intrautrerine device :Knowledge and factors affecting acceptance among pregnant/parturant women attending a large tertiary care center in Puducherry, India,Dept of Obstetrics and gyanecology,Jawaharlallnstitude Of Postgraduate medical Education and research, Puduccharylndia.Int $J$ Adv Med Health Resv[serial online ]2017 [cited $2020 \quad$ Apr 25];4:6974.htp://www.ijamhrjournal.org/text.asp?2017/4/2/69/221578.

17. 17. Safwat A, Mohamed Momen A Kamel Omar M.Shaaban,HossamT.Salem, Acceptability for use of Postpartum Intrauterine Contraceptive Devices: Department of obstetrics and gyanecology ,Faculty Medicine ,Assiut University, Assiut , Egypt, Med PrincPract 2003;12:12;170— 175. www.karger.com/mpp

18. Dr Mahbur Rehaman ,DrNirmallyaSaha Brig, DrAa.k. Sirivastava Col( DR AK Sood, Acceptance of immediate postpartum intrauterine contraceptive device (ppiucd) insertion by pregnant womenIOSR Journal of Dental and Medical Sciences 2279-0861. Vol 17,issue 3 Ver.15,March (2018),PP36—40 www.ios journals.org 